\title{
Answer and discussion: Cardiovascular imaging quiz case
}

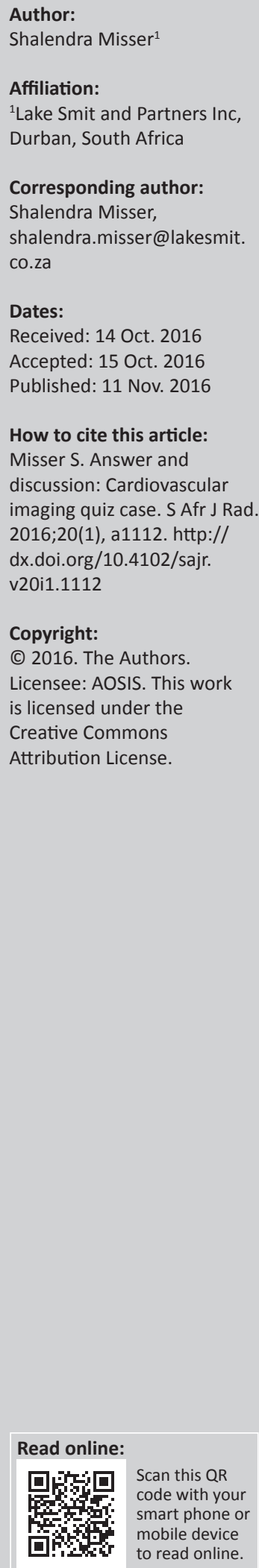

A 32-year-old woman presented with shortness of breath, NYHA grade 2-3, becoming progressively worse and affecting her activities of daily living. She underwent extensive investigations shown in the series of images including chest radiograph, abdominal sonar, computed tomography of chest and abdomen as well as a cardiac magnetic resonance imaging study.

There were several submissions received with satisfactory approaches to the clinico-radiological question posed. A noteworthy response was submitted by Dr Amjed Kadhim from Iraq. The most comprehensive answer and approach to the diagnosis was, however, received from Dr Fourie Bezuidenhout who is the winner of this quiz case. Congratulations to Dr Bezuidenhout on winning the prize of R2000 sponsored by the RSSA.

\section{Answer}

A 32-year-old woman presented with shortness of breath, NYHA grade 2-3, becoming progressively worse and affecting her activities of daily living. She underwent extensive investigations shown in the series of images including chest radiograph, abdominal sonar, computed tomography of chest and abdomen as well as a cardiac magnetic resonance imaging (MRI) study.

The chest X-ray (Figure 1) performed on admission demonstrated a reticulonodular pattern of lung field opacification with areas of coalescent consolidation. Right paratracheal and hilar lymphadenopathy was noted as well as a shallow left lower mid-zone surface convexity pleural reaction. Wasting of the soft tissues was indicative of chronicity or systemic disease.

Ultrasound of the liver (Figure 2) revealed hepatomegaly with multiple rounded and ovoid foci of reduced echogenicity surrounded by echogenic halos in both lobes of the liver. No increased vascularity, calcification or central necrosis was shown in any of the lesions. The portal venous system and the biliary tree were otherwise normal. There was no significant enlargement of the spleen or focal splenic lesion identified; however, a coarse echo texture of the spleen was noted. A few sub-centimetre para-aortic nodes were also documented. There was no ascites and the rest of the abdominopelvic sonar was unremarkable (Figure 3).

Computerised tomography (CT) scan of the abdomen demonstrated the multiple hepatic lesions with isodense to slightly hyperdense central lesion density and surrounding low attenuation margin on the precontrast acquisition. The lesions did not demonstrate significant post-contrast enhancement, and they appeared hypodense to surrounding hepatic parenchyma on the portal venous phase study. Fleshy para-aortic nodes were noted in Figure 4 with no significant central necrosis.

$\mathrm{CT}$ of the lung bases (Figures 5a and Figure 6) identified extensive peribronchovascular nodules in the parahilar and centrilobular interstitial compartments. There was subsegmental ground glass opacity, and areas of consolidation noted in the lower zones of both lungs. The left pleural effusion and minimal pleural thickening was also noted. Figure $5 \mathrm{~b}$ shows a clear demarcation of abnormal myocardial thickening and reduced enhancement of the interventricular septum and adjacent left ventricle (annotated by the arrows). The appearance suggests myocarditis or oedema of the ventricular and septal wall.

ECG-gated cardiac MRI was arranged in the light of suspected cardiomyopathy to account for the progressive dyspnoea. Axial dual-chamber T2-weighted MRI of the heart demonstrated corresponding hyperintensity in the left ventricular wall and the mid- and basal interventricular 
septum in keeping with myocardial oedema (annotated by the arrows) (Figure 7). A heterogenous pattern of enhancement is shown on the post-gadolinium (TRUFI) study with areas of non-perfusion in the early phase of the dynamically enhanced sequence (annotated by the arrows) and equivalent areas of delayed gadolinium-induced enhancement on the subsequent images up to 12 minutes post-injection (annotated by the

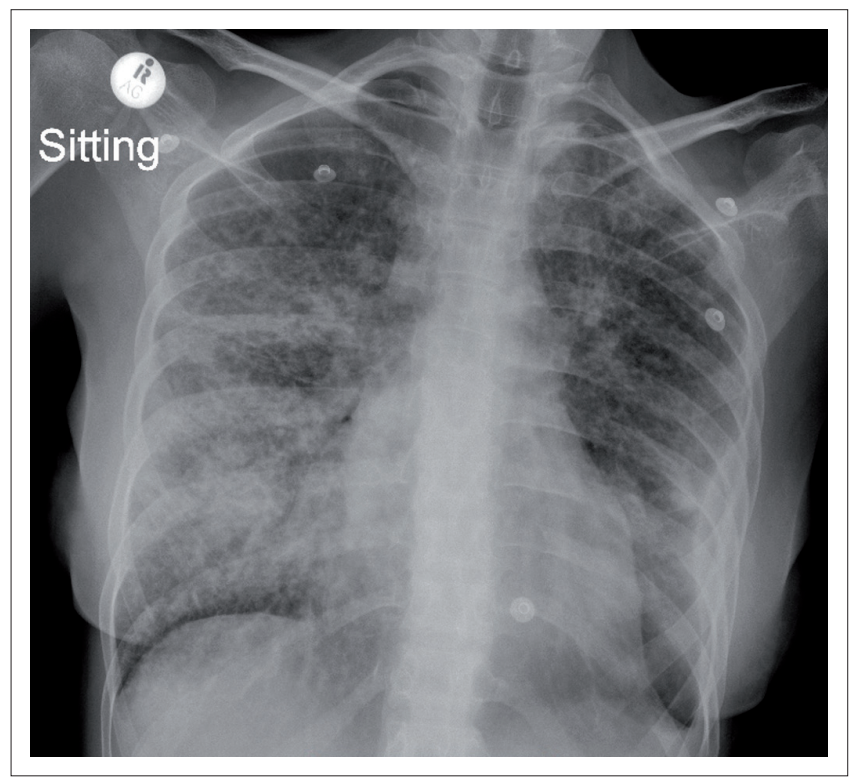

FIGURE 1: Chest radiograph performed on admission. arrows) (Figure 8). This was shown to involve epicardial and mid-myocardial portions of the ventricular and septal wall crossing multiple vascular territories. A sliver of pericardial fluid was noted at the apical region. The right ventricle appeared to be spared and the cardiac valves visualised were normal. The lung field changes were again noted.

Haematological and biochemical tests revealed mild anaemia, infiltrative pattern on the liver function test with elevation of the alkaline phosphatase and gamma-glutamyl transferase as well as raised serum angiotensin converting enzyme level at 117.9U/L (normal 8-52). Echocardiogram confirmed reduced myocardial contractility with an ejection fraction of $40 \%$.

A final diagnosis was made of multisystem disease with pleuro-pulmonary, hepatic and cardiac abnormalities compatible with granulomatous infiltration because of disseminated sarcoidosis.

\section{Discussion}

The concept of sarcoidosis was first introduced in 1877 by Jonathan Hutchinson, in a patient with cutaneous manifestations of a granulomatous disease. ${ }^{1}$ Carl Boeck demonstrated the cutaneous lesions described by Hutchinson in a number of illustrations but these were never published. It was only in 1899 when the nature of the disorder was really appreciated after his grandson, Caesar Boeck,

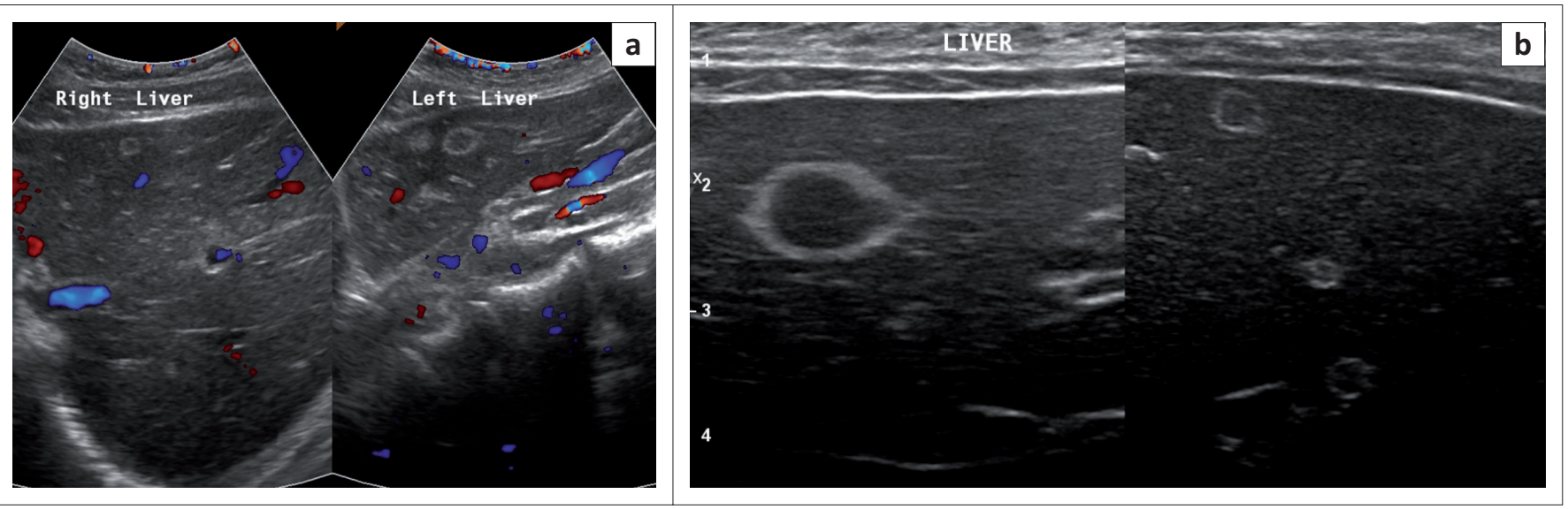

FIGURE 2: (a) Colour duplex sonar image of the liver and (b) B-mode higher frequency sonar image of the liver.
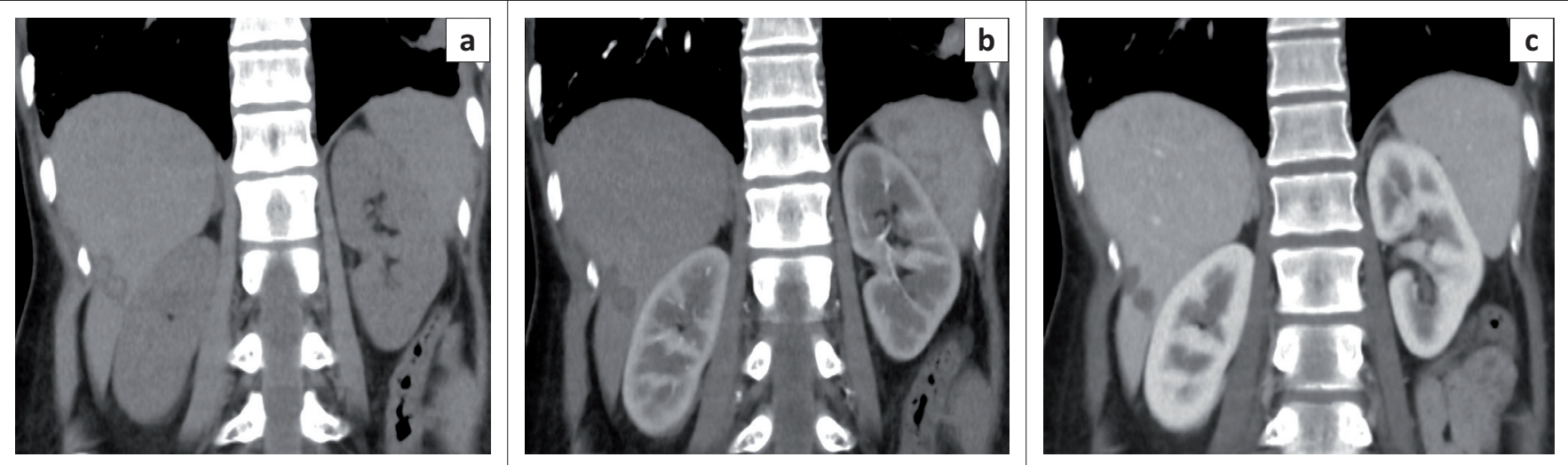

FIGURE 3: Coronal reformatted CT images of the liver: (a) precontrast study, (b) arterial phase and (c) portal venous phase. 

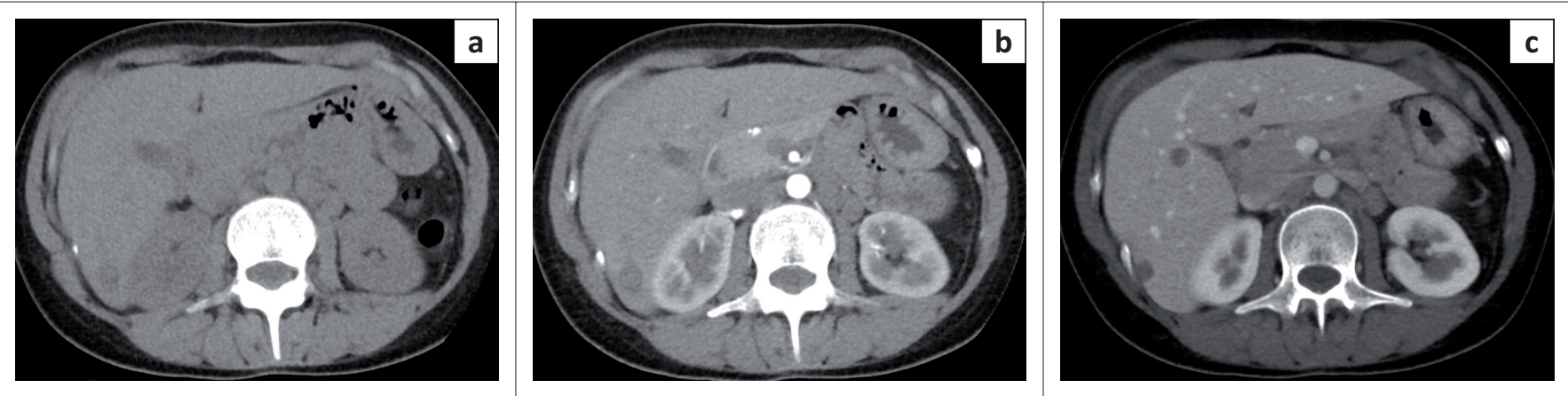

FIGURE 4: Axial CT images of the upper abdomen: (a) precontrast study, (b) arterial phase and (c) portal venous phase.
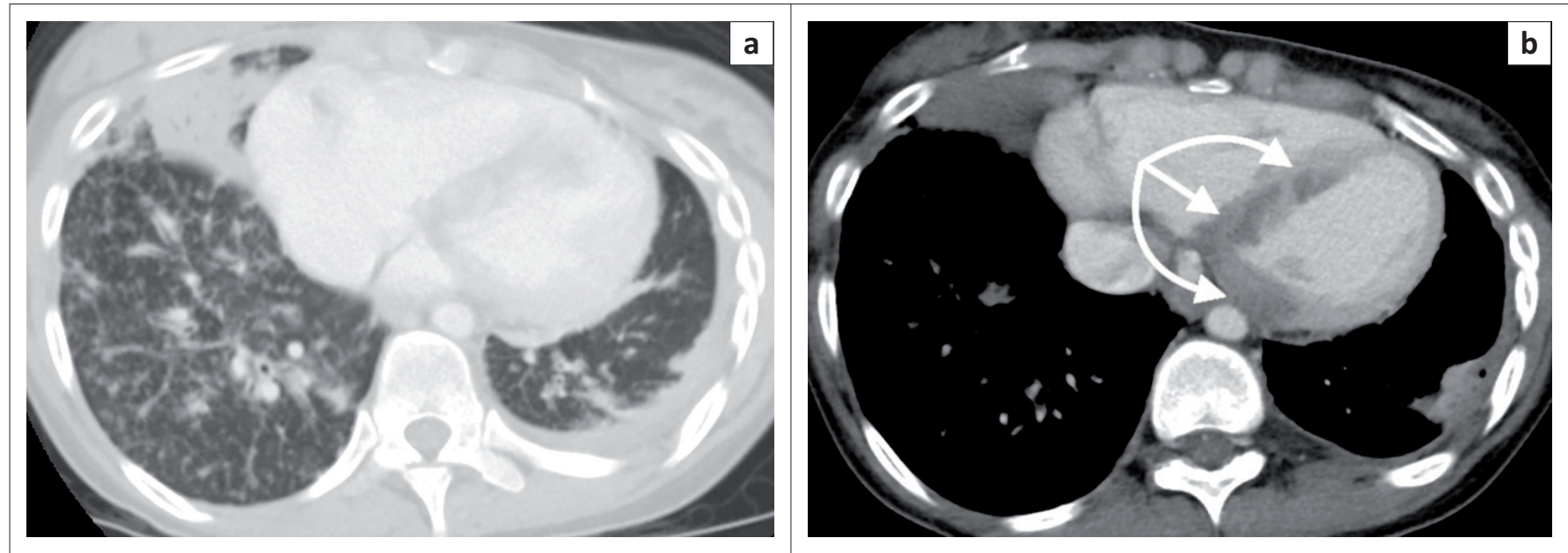

FIGURE 5: Axial CT images of (a) the lower lung fields and (b) at level of left ventricle.

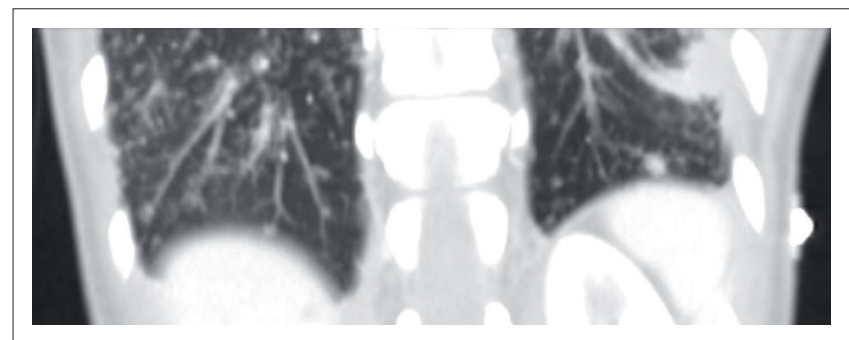

FIGURE 6: Coronal reformatted CT images of the lower lung fields.

published a case study of a patient with what he termed Sarkoid, meaning resembling a sarcoma but with benign features. ${ }^{2}$ The term sarcoidosis arose from this report and it has remained to this day.

Sarcoidosis is a multisystem granulomatous disease characterised by the presence of non-caseating granulomas in the affected organs. Although sarcoidosis typically presents with paratracheal and bilateral hilar lymphadenopathy as well as pulmonary infiltration, it has been shown to affect any organ system. Table 1 lists the spectrum of disorders associated with sarcoidosis referable to each organ system. Pulmonary and lymphatic involvement are most common, documented in $90 \%$ and $30 \%$ of cases, respectively. ${ }^{3}$ Extrapulmonary manifestations in the central nervous system, abdominal viscera and cardiovascular system are variably expressed in different population groups under the influence of demographic, environmental and genetic factors.

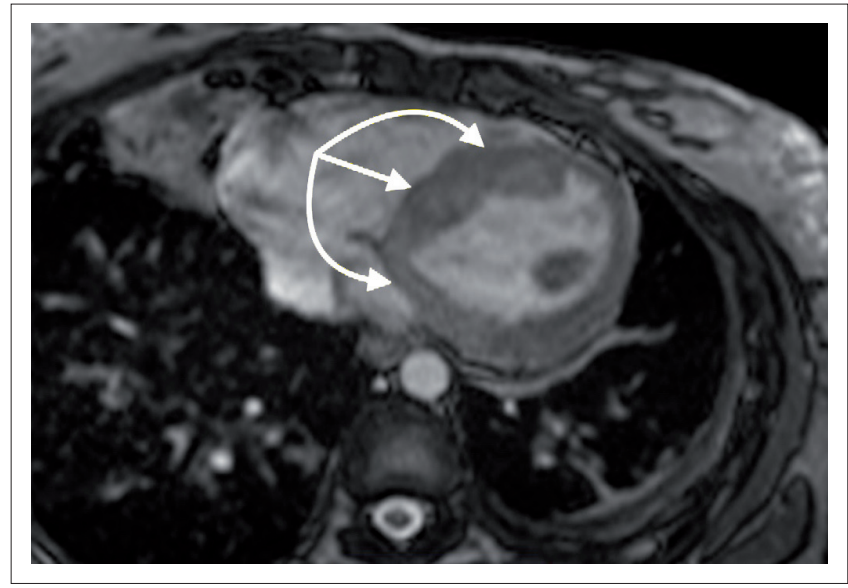

FIGURE 7: Axial dual-chamber cardiac T2-weighted MRI image.

The disease, however, does occur in all races, both sexes and all ages. There is a distinct predilection for young adults under 40 years of age, peaking in women in the late third decade. A second peak is noted in the sixth decade. Death because of sarcoidosis is estimated at $1 \%-5 \%$ in different population groups. Apart from Japan, where cardiac sarcoidosis (CS) is the principle extrapulmonary manifestation and commonest cause of death, in the rest of the world respiratory failure is the leading cause of death. ${ }^{4}$

Sarcoidosis occurs in genetically susceptible individuals who are exposed to certain suspected environmental agents. 

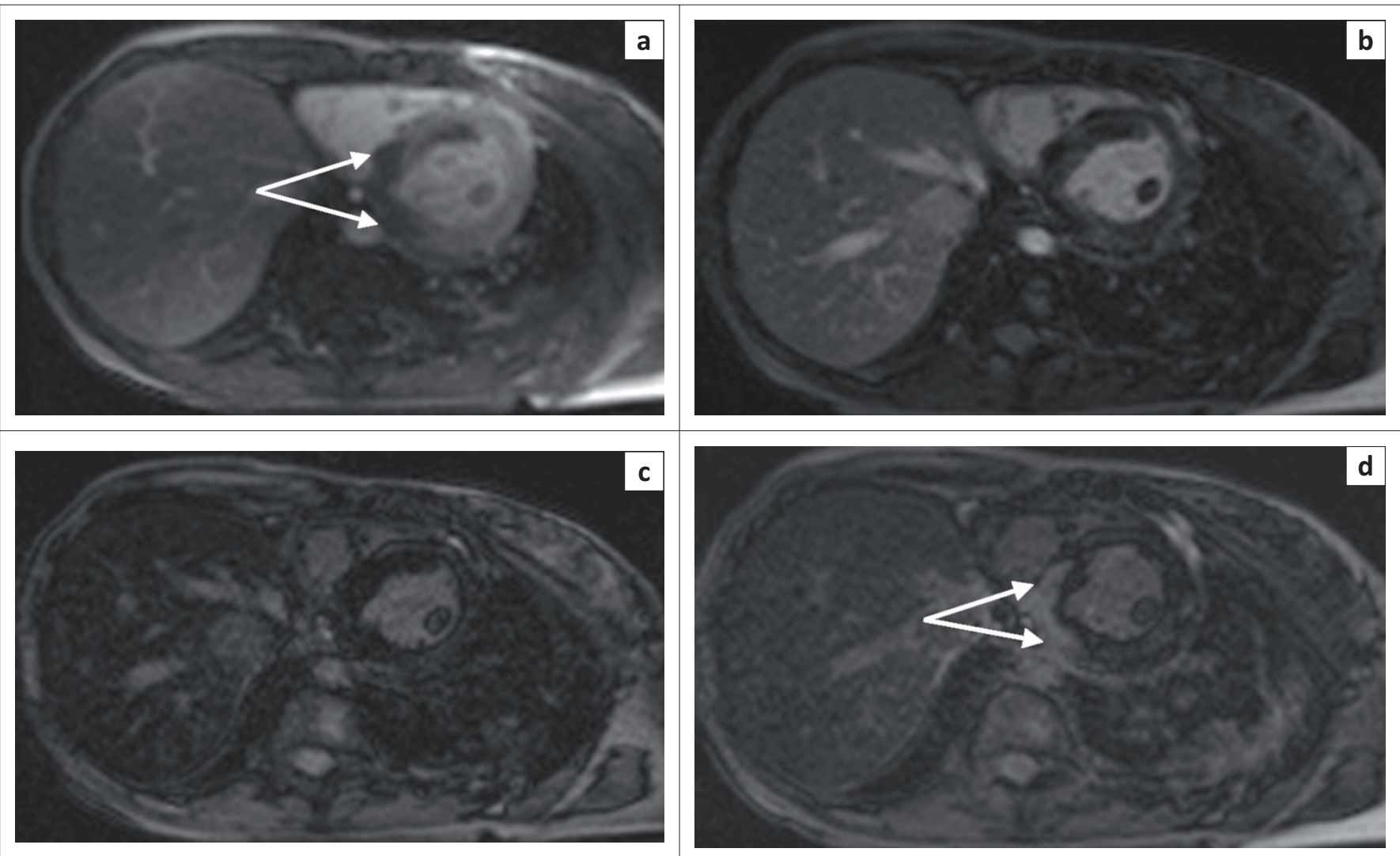

FIGURE 8: Axial post-contrast TRUFI MR images performed at time intervals after intravenous gadolinium injection: (a) dynamic, (b) 2 minutes, (c) 5 minutes and (d) 12 minutes delay.

TABLE 1: Spectrum of disorders associated with sarcoidosis referable to each organ system. $3,4,5,6,7,8,9$

\begin{tabular}{|c|c|}
\hline Organ or system & Clinical abnormality or syndrome \\
\hline Lungs & Granulomatous inflammation, fibrotic lung disease \\
\hline Lymphatics & Lymph node enlargement, generally painless \\
\hline Liver & $\begin{array}{l}\text { Granulomas, infiltration with fibrosis, cholestatic syndrome, } \\
\text { cirrhosis, portal hypertension and liver failure }\end{array}$ \\
\hline Central nervous system & Cranial nerve palsies, meningitis, parenchymal involvement \\
\hline Ophthalmological & Uveitis, optic neuritis \\
\hline Heart & $\begin{array}{l}\text { Myocarditis, reduced left ventricular ejection fraction, } \\
\text { complete heart block, ventricular fibrillation, tachycardia }\end{array}$ \\
\hline Skin & Erythema nodosum, lupus pernio, plaques and nodules \\
\hline Salivary glands & Heerfordt syndrome \\
\hline Musculoskeletal & Granulomatous arthritis, myositis \\
\hline
\end{tabular}

These include infectious microbes (such as Mycobacteria), organic agents (e.g. pine tree pollen) and inorganic substrates (e.g. zirconium) which are proposed to incite a T-cellmediated response triggered by underlying genetic predisposition particularly referable to the (Human leukocyte antigen) HLA phenotypes. These sequentially result in a cascade of cytokine and other inflammatory cell-mediated processes that cause accumulation of T-lymphocytes and macrophages at the sites of inflammation in the affected organ. ${ }^{5}$

The typical sarcoid lesion comprises non-caseating epithelioid cell granulomata. These can occur in any organ and the course of the granuloma is variable. In the lungs, these granulomas are located along the connective tissue sheaths around arteries, venules and bronchoalveolar airways and manifest as parahilar peribronchovascular
TABLE 2: Stage of sarcoidosis and features on chest radiography including percentage of patients seen with the particular stage at initial presentation and the corresponding prognosis for each stage. ${ }^{8}$

\begin{tabular}{llcc} 
Stage & Description & $\begin{array}{c}\text { Patients at presentation } \\
(\mathbf{\%})\end{array}$ & $\begin{array}{c}\text { Possibility of remission } \\
(\mathbf{\%})\end{array}$ \\
\hline 0 & No abnormality & $5-10$ & $70-95$ \\
1 & Lymphadenopathy & 50 & $60-90$ \\
2 & $\begin{array}{l}\text { Lymphadenopathy + } \\
\text { pulmonary infiltrates }\end{array}$ & $25-30$ & $40-70$ \\
3 & Pulmonary infiltration & $10-12$ & $10-20$ \\
\hline 4 & Pulmonary fibrosis & 5 & 0 \\
\hline
\end{tabular}

interstitial thickening. ${ }^{6}$ This thickening may be smooth or nodular. Subpleural pulmonary parenchymal and pleural granulomas appear as subpleural nodules along the surface convexities of the lungs.

Conglomeration of several granulomas in the presence or absence of fibrosis appears as ground glass opacity which is localised to the alveolar septa and perivascular interstitium. Nodules exceeding $1 \mathrm{~cm}$ in size are because of coalescent granulomas and may appear as focal areas of consolidation. These can progress to form masses and may mimic infection, cryptogenic organising pneumonia or bronchiolo-alveolar carcinoma. ${ }^{7}$ Siltzbach classification of sarcoidosis, albeit nearly five decades old, is still in worldwide clinicoradiological use daily. ${ }^{8}$ Table 2 shows the value of this system as a useful prognostic tool.

High-resolution CT is superior to chest radiography and conventional $\mathrm{CT}$ in the discrimination of active inflammation from fibrotic lung disease. This is a critical aspect of diagnosis 
as the presence of fibrosis (which demonstrates septal lines, architectural distortion, honeycombing, bulla and traction bronchiolectasis) indicates an irreversible process, whereas inflammation (manifested by ground glass opacity, nodules and alveolar opacities) will be responsive to therapy. ${ }^{7}$ In addition, these several features of sarcoidosis that can be categorised as either typical or atypical features is summarised in Table 3.

The liver is the third visceral site of sarcoidosis infiltration after pulmonary and lymphatic involvement. It is estimated that $10 \%-25 \%$ of patients can have hepatic sarcoidosis. ${ }^{9}$ The commonest imaging abnormality is hepatomegaly with diffuse isoechogenicity of the liver. Increased hepatic echogenicity, indistinguishable from hepatic steatosis, is also possible. A coarsened echo texture may be attributed to coalescence of multiple granulomas and surrounding fibrosis. Although at biopsy hepatic granulomas are demonstrable in up to $60 \%-80 \%$ of specimens, only $5 \%$ of cases have lesions that can be shown using radiological imaging by sonar or $\mathrm{CT} .{ }^{10}$ It is quite unusual to see these granulomas at ultrasound. They typically have a low central echogenicity and occasionally a surrounding echogenic halo. They are usually not associated with much architectural distortion, and the rest of the hepatic parenchyma may appear otherwise normal. Hepatic granulomas, which range from $1 \mathrm{~mm}$ to $2 \mathrm{~mm}$ up to a few centimetres in size, may also be isoechoic to liver and could potentially be sonographically occult in a number of patients, only to be discovered on crosssectional imaging studies subsequently performed. Generally, hepatic granulomas show reduced vascularity. They could be difficult to sonographically distinguish from other causes of granulomas (including tuberculosis and systemic lupus), regenerating nodules in cirrhosis, hepatic adenomas or metastases. Primovist MRI studies and multiphasic CT examinations are able to further characterise the lesions. Liver disease in sarcoidosis is reportedly a quiescent disease but can result in a cholestatic syndrome (with pruritus and jaundice), portal hypertension and hepatic failure. The latter is seen in only $1 \%$ of patients with sarcoidosis. ${ }^{9}$

\begin{tabular}{|c|c|c|}
\hline Features & Variable & Symptoms \\
\hline \multirow[t]{4}{*}{ Typical } & Lymphadenopathy & $\begin{array}{l}\text { - } \quad \text { Hilar, bilateral, non-necrotic } \\
\text { Paratracheal }\end{array}$ \\
\hline & $\begin{array}{l}\text { Nodules } \\
\text { (Inflammation) }\end{array}$ & $\begin{array}{ll}\text { - } & \text { Micronodules }(2-4 \mathrm{~mm}) \\
\text { - } & \text { Macronodules }(>5 \mathrm{~mm}) \\
\text { - } & \text { Subpleural }\end{array}$ \\
\hline & $\begin{array}{l}\text { Fibrotic changes } \\
\text { (Irreversible) }\end{array}$ & $\begin{array}{l}\text { - Interlobular septal thickening } \\
\text { - } \quad \text { Architectural distortion } \\
\quad \text { Volume loss, traction bronchiectasis }\end{array}$ \\
\hline & Zone predilection & $\begin{array}{l}\text { - } \quad \text { Upper and mid-zones, bilateral perihilar } \\
\text { Lymphangitic spread }\end{array}$ \\
\hline \multirow[t]{4}{*}{ Atypical } & Lymphadenopathy & $\begin{array}{ll}- & \text { Unilateral } \\
- & \text { Single group involvement }\end{array}$ \\
\hline & $\begin{array}{l}\text { Parenchymal } \\
\text { opacities }\end{array}$ & $\begin{array}{ll}- & \text { Miliary nodules } \\
\text { - } & \text { Consolidation } \\
\text { - } & \text { Mibrocystic changes } \\
& \text { Mosaic pattern of attenuation }\end{array}$ \\
\hline & Pleural disease & $\begin{array}{ll}\text { - } & \text { Effusion } \\
\text { - } & \text { Thickening, calcification } \\
& \text { Chylothorax, haemothorax }\end{array}$ \\
\hline & $\begin{array}{l}\text { Complications of } \\
\text { stage } 4 \text { sarcoidosis }\end{array}$ & $\begin{array}{ll}\text { - } & \text { Mycetoma } \\
\text { - } & \text { Aspergilloma }\end{array}$ \\
\hline
\end{tabular}

Cardiac involvement in sarcoidosis is principally because of infiltration of the myocardium by sarcoid granulomas. Although only $7 \%$ of patients with sarcoidosis present with cardiac symptoms, autopsy studies variably indicate $20 \%$ $50 \%$ may have cardiac disease. ${ }^{12,13}$ CS was first described in 1929 at a post-mortem examination that revealed epicardial granulomas in a patient that had similar skin lesions. ${ }^{14}$ The diagnosis of CS can only be proven on histology by subendocardial biopsy, but expertise to perform this biopsy is not always available and the diagnostic yield thereof is suboptimal. Currently, the diagnosis may be inferred through the abnormalities induced on electrocardiogram, echocardiogram or MRI in the presence of extracardiac sarcoidosis. ${ }^{15,16}$ The diagnostic criteria most widely accepted are listed in Table 4.

The classic clinical presentation is that of heart block; however; other conduction abnormalities including ventricular tachycardia (sustained or non-sustained most commonly because of re-entry circuit abnormality), supraventricular arrhythmia or ventricular fibrillation are described. ${ }^{17}$ Some patients develop cardiomyopathy that may progress to cardiac failure. Sudden cardiac death is a feared complication in CS. Pathologically, the classic CS lesion is a non-caseating epithelioid cell granuloma containing T-lymphocytes and macrophages. The lesions may be identified in one of three phases of the inflammatory process. Early inflammatory changes show lymphocytes and a few giant macrophages with small granulomas. In the intermediate phase, well-formed granulomas are demonstrated, and in the late stage, fibrosis with few granulomas and chronic inflammatory cells predominate.

Echocardiography is useful in the detection of regional wall motion abnormalities or other morphologic abnormalities including ventricular aneurysms, basal septal thinning and ventricular wall thickening. Dilatation of the left ventricle and reduced ejection fraction are poor prognostic factors. CT is not routinely performed for cardiac assessment; however,

TABLE 4: Japanese Ministry of Health and Welfare (JMHW) 2007 revised guidelines for the diagnosis of cardiac sarcoidosis. ${ }^{15}$

\begin{tabular}{|c|c|c|}
\hline Guideline & Variable & Result \\
\hline \multirow[t]{2}{*}{ Diagnosis } & Histologic & $\begin{array}{l}\text { CS confirmed by endomyocardial biopsy showing } \\
\text { non-caseating epithelioid cell granulomas with } \\
\text { histologic or clinical diagnosis of extracardiac } \\
\text { sarcoidosis. }\end{array}$ \\
\hline & Clinical & $\begin{array}{l}\text { Endomyocardial biopsy does not show non-caseating } \\
\text { epithelioid cell granulomas, extracardiac sarcoidosis } \\
\text { was diagnosed histologically or clinically and there } \\
\text { are at least two major criteria or one major and } \\
\text { more than two minor criteria satisfied. }\end{array}$ \\
\hline \multirow[t]{2}{*}{ Criteria } & Major & $\begin{array}{l}\text { - } \quad \text { Advanced atrioventricular block } \\
\text { Basal thinning of the interventricular septum } \\
\text { - } \quad \text { Positive gallium uptake in the heart } \\
\text { fraction }(<50 \%) \text { left ventricular ejection } \\
\text { fran }\end{array}$ \\
\hline & Minor & $\begin{array}{l}\text { - } \quad \text { Abnormal ECG findings (ventricular } \\
\text { arrhythmias) } \\
\text { - Abnormal echocardiographic findings (regional } \\
\text { wall motion abnormality) } \\
\text { - Nuclear medicine findings (perfusion defect } \\
\text { on myocardial scintigraphy) } \\
\text { - } \quad \text { MRI findings (delayed and/or late gadolinium- } \\
\text { induced myocardial enhancement) } \\
\text { - Endomyocardial biopsy findings: Interstitial } \\
\text { fibrosis and/or monocyte infiltration }\end{array}$ \\
\hline
\end{tabular}

CS, cardiac sarcoidosis. 
at the time of High-resolution computed tomography (HRCT) performed for assessment of pulmonary disease, one may demonstrate cardiomegaly, variable myocardial thickness, pericardial disease and presence of aneurysms. These changes are better appreciated on ECG-gated cardiac multidetecor CT studies. ${ }^{18}$

Cardiac MRI has become a critical aid to the diagnosis of CS as it is an excellent modality to demonstrate morphologic and functional characteristics of cardiomyopathies. Dedicated cardiac phased array-coils utilised with ECGtriggering improve spatial and contrast resolution for better lesion detection. There remains a challenge in the imaging of patients with intracardiac defibrillators or pacemakers in situ, but these are no longer an absolute contraindication with MRI-compatible units now widely available. T2-weighted fast spin echo images usually in short axis depict the inflammatory changes of acute phase of CS as focal areas of increased signal intensity. These may be associated with variable wall thickness showing areas of T2-weighted hyperintensity or early phase enhancement after gadolinium. This is compatible with inflammatory change and related oedema. ${ }^{18}$ Granulomas may also be seen as focal nodular areas of similar signal change. Cine cardiac MRI sequences can demonstrate areas of regional wall motion abnormality or ventricular hypokinesia associated with severe myocardial infiltration. The latter progresses to congestive cardiomyopathy with heart failure.

Late gadolinium-induced enhancement, most commonly affecting the lateral walls and basal septum, may show the true extent of myocardial infiltration beyond vascular territories indicative of a non-ischaemic aetiology. Typically transmural, mid-myocardial or subepicardial patterns of enhancement are demonstrated. This is in contradistinction to the subendocardial pattern seen in ischaemia-related delayed post-gadolinium enhancement encountered in coronary artery disease. There is a strong correlation between the extent of late gadolinium enhancement of the myocardium and disease severity as well as prognostic outcome. ${ }^{19}$ Improvement in the extent of myocardial signal abnormality and reduction in post-gadolinium enhancement are seen after therapy. ${ }^{18}$

Radionuclide imaging techniques are also used to assess myocardial perfusion and infiltration. Thallium 201 and technetium $99 \mathrm{~m}$ cardiac-scintigraphy scans performed at rest show areas of reduced isotope uptake in the myocardium of patients with CS. These perfusion defects are largely because of fibrogranulomatous change in the myocardium or may be related to localised small vessel vasoconstriction or other metabolic processes. ${ }^{20}$ Upon exercising, these perfusion defects may resolve or become less appreciable indicating a reversedistribution pattern in CS when compared with ischaemic cardiomyopathy. More recently, 18F-fluorodeoxyglucose positron emission tomography (PET) has gained much recognition as the superior radionuclide imaging modality for
CS assessment. It can be used to show disease activity by highlighting the areas of active inflammatory change as well as identifying perfusion defects because of fibrogranulomatous destruction of the myocardium in scarring. The sensitivity of PET for diagnosis of CS has been estimated at $82 \%-100 \%$ in recent studies. ${ }^{18,20}$

The prognosis in CS is variable and depends on the stage at which the patient presents, the extent of extrapulmonary dissemination, NYHA functional class, left ventricular dysfunction and the presence of sustained arrhythmia. CS therefore, despite being a relatively rare condition, is a potentially fatal manifestation of sarcoidosis and a leading cause of death in this multisystem disease. Clinical, radiological and pathological correlation and consultation is crucial to the successful early diagnosis and effective treatment of CS.

\section{Acknowledgements Competing interests}

The author declares that he has no financial or personal relationships which may have inappropriately influenced him in writing this article.

\section{References}

1. Hutchinson J. Case of livid papillary psoriasis. In: Illustrations of clinical surgery. Volume 1. London: J\&A Churchill, 1877; p. 42-43.

2. Boeck C. Multiple benign hud-sarkoid. Norsck Laegevidensk. 1899;60:1321.

3. Statement on sarcoidosis. Joint Statement of the American Thoracic Society (ATS), the European Respiratory Society (ERS) and the World Association of Sarcoidosis and Other Granulomatous Disorders (WASOG) adopted by the ATS Board of Directors and by the ERS Executive Committee, February 1999. Am J Respir Crit Care Med. 1999;160(2):736-755.

4. Gideon NM, Mannino DM. Sarcoidosis mortality in the United States 1979-1991: An analysis of multiple-cause mortality data. Am J Med. 1996;100:423-427. http://dx.doi.org/10.1016/S0002-9343(97)89518-6

5. Miller BH, Rosado-de-Christenson ML, McAdams HP, Fishback NF. Thoracic sarcoidosis: Radiologicpathologic correlation. Radiographics. 1995;15(2):421-437. http://dx.doi.org/10.1148/radiographics.15.2.7761646

6. Nishimura $\mathrm{K}$, Itoh $\mathrm{H}$, Kitaichi $\mathrm{M}$, Nagai $\mathrm{S}$, Izumi T. Pulmonary sarcoidosis: Correlation of CT and histopathologic findings. Radiology. 1993;189(1):105-109. http://dx.doi.org/10.1148/radiology.189.1.8372178

7. Criado E, Sánchez M, Ramírez J, et al. Pulmonary sarcoidosis: Typical and atypical manifestations at high-resolution CT with pathologic correlation. Radiographics. 2010;30(6):1567-1586. http://dx.doi.org/10.1148/rg.306105512

8. Siltzbach LE. Sarcoidosis: Clinical features and management. Med Clin North Am. 1967;51(2):483-502. http://dx.doi.org/10.1016/S0025-7125(16)33069-3

9. Iannuzzi MC, Rybicki BA, Teirstein AS. Sarcoidosis. N Engl J Med. 2007;357(21): 2153-2165. http://dx.doi.org/10.1056/NEJMra071714

10. Warshauer DM, Lee JKT. Imaging manifestations of abdominal sarcoidosis. Am J Roentgenol. 2004;182(1):15-28. http://dx.doi.org/10.2214/ajr.182.1.1820015

11. Kessler A, Mitchell DG, Israel HL, Goldberg BB. Hepatic and splenic sarcoidosis: Ultrasound and MR imaging. Abdom Imaging. 1993;18(2):159-163. http://dx.doi. org/10.1007/BF00198055

12. Matsui $Y$, Iwai $K$, Tachibana $T$, et al. Clinicopathological study of fatal myocardial sarcoidosis. Ann N Y Acad Sci. 1976;278:455-469. http://dx.doi.org/10.1111/ j.1749-6632.1976.tb47058.x

13. Silverman KJ, Hutchins GM, Bulkley BH. Cardiac sarcoid: A clinicopathologic study of 84 unselected patients with systemic sarcoidosis. Circulation. 1978;58: 1204-1211. http://dx.doi.org/10.1161/01.CIR.58.6.1204

14. Bernstein M, Konzlemann FW, Sidlick DM. Boeck's sarcoid: Report of a case with visceral involvement. Arch Intern Med. 1929;44(5):721-734. http://dx.doi. org/10.1001/archinte.1929.00140050098009

15. Sarcoidosis Diagnostic Criteria Revising Committee. Diagnostic standard and guidelines for sarcoidosis. Jpn J Sarcoidosis Granulomatous Dis. 2007;27: 89-102.

16. Yoshida $Y$, Morimoto $S$, Hiramitsu $S$, et al. Incidence of cardiac sarcoidosis in Japanese patients with high-degree atrioventricular block. Am Heart J. 1997;134:382-386. http://dx.doi.org/10.1016/S0002-8703(97)70070-X 
17. Birnie DH, Sauer WH, Bogun F. HRS expert consensus statement on the diagnosis and management of arrhythmias associated with cardiac sarcoidosis. Heart Rhythm. 2014;11(7):1305-1323. http://dx.doi.org/10.1016/j.hrthm.2014.03.043

18. Jeudy J, Burke AP, White CS, Kramer GBG, Frazier AA. Cardiac sarcoidosis: The challenge of radiologic-pathologic correlation. Radiographics. 2015;35:657-679. http://dx.doi.org/10.1148/rg.2015140247
19. Shafee MA, Fukuda K, Wakayama Y, et al. Delayed enhancement on cardiac magnetic resonance imaging is a poor prognostic factor in patients with cardiac sarcoidosis. J Cardiol. 2012;60(6):448-453. http://dx.doi.org/10.1016/j. jjcc.2012.08.002

20. Kim JS, Judson MA, Donnino R, et al. Cardiac sarcoidosis. Am Heart J. 2009;157(1):9-21. http://dx.doi.org/10.1016/j.ahj.2008.09.009 